\title{
More Technology, Better Childhoods? The Case of the Portuguese 'One Laptop per Child' Programme
}

\author{
Sara Pereira ${ }^{1}$ \\ Communication and Society Research Centre \\ University of Minho, Portugal
}

doi:10.5937/comman1329171P

Summary: In 2008, the XVII Portuguese socialist government launched the initiative 'e.escolinha' as a programme within its 'Technological Plan for Education'. This initiative aims to ensure access for all primary school children to a personal computer named 'Magalhäes' with educational content and generalize the use of computers and the Internet in early learning. This paper presents a documental analysis of policy documents, complemented by interviews of policy makers, examining the ways children and children media users are (re)presented. We started from the position that these sources draw on both of these conceptions in order to present the 'e.escolinha' initiative, and we are interested in a deconstruction of those notions. Based on questionnaires administered to children aged 8-10 years old, the paper also focuses on the ways children experienced this policy. We find that this policy is more centred on access to technology and the Internet than on children. The child is conceived in terms of his or her future, seen as an adult in the making. Technology is a kind of passport to the future, enabling success in a competitive labour market. In general, the sources reveal an idealised political vision of the benefits of technology for the teaching and learning process and for children's educational success, which contrasts with both the way the children experienced this policy and mainly with the way that the children use the 'Magalha'es' computer. We conclude by discussing the importance of taking into account the socially and politically constructed nature of technology and emphasizing the social dimensions of use and access.

Keywords: one laptop per child, child, education, political discourse, information society, technology

\footnotetext{
1 sarapereira@ics.uminho.pt
} 


\section{Introduction}

Today's children live mediatized childhoods and it is no longer possible to contemplate children's social and cultural worlds without considering the role played by the media. In fact, the media have an enormous impact on societies and people's lives. Therefore, there is a huge concern, at least in western societies, that all citizens have access to digital technologies. In Europe, this has originated recommendations and deliberations from both the European Commission and the European Parliament, and the governments of some countries have created specific technological plans for education. Their main objectives are to prepare new generations for the challenges posed by the knowledge society and to develop students' ICT skills. It was specifically with this purpose that in 2007 the XVII Portuguese government launched its 'Technological Plan for Education'. This plan comprises, among others, the 'e.escolinha' (e.little school) programme, which aims to provide access to laptops with learning resources to primary school children (6-10 years old). Parents can obtain these laptops (named 'Magalhães', a tribute to the Portuguese navigator Fernão de Magalhães) for free or acquire them at a small cost. This governmental initiative was presented to society with considerable enthusiasm by the former Prime Minister, believing that in some way it would contribute to 'better childhoods'.

In fact, this was a period of great financial investment in new technologies, partly due to the compensations provided by mobile operators for the development of the Information Society. However, after a governmental change in 2011, the programme was discontinued given the context of the current crisis the country has been facing and some political divergences. Despite the discontinuation, from 2008/2009 to 2010/2011 the 'e.escolinha' gave access to a personal computer to approximately 750,000 children. Comparing data from the Ministry of Education ${ }^{2}$, in the academic year of 2005/2006, before the implementation of the measure, the ratio of students per computer, in the 1 st cycle of basic education, was 15:9 in public schools and 9:5 in private schools. This number decreased dramatically in the year 'Magalhães' laptops were distributed, in 2008/2009, to 1:1 and 1:2 in public and in private schools, respectively. However, only one year after the implementation of the initiative,

\footnotetext{
2 Source: GEPE/ DGEEC, Estatísticas da Educação [Education Statistics] 2008/2009, 2009/2010 e 2010/2011.
} 
the ratio of students per computer reached the maximum ratio of 1:1 in both schools. The same scenario is present in the number of pupils per computer with an Internet connection, although with a greater difference: from 26:5 in public schools and 13:8 in private schools, in 2005/2006, to a ratio of $1: 1$ and 1:2 correspondingly, in 2008/2009.

However, despite the public investment, according to the EU Kids Online survey, "there is a gap between the digital infrastructure and economic and educational conditions in which the Internet can be fully enjoyed" (Ponte, 2012). This means that while the access was fully granted, placing Portugal in the lead in terms of children's ownership of personal laptops and in third, after Denmark and Sweden, regarding children accessing the Internet in their bedrooms (Ponte, 2012), when it comes to use of the Internet, only 55\% of Portuguese children are frequent users, far behind the leader, Sweden (84\%).

All the propaganda about this governmental programme praised the technology and its role in successfully modernizing education (Pereira and Pereira, 2013). The technology and access gained such importance that the children sometimes seemed to be absent from this programme. Nevertheless, they are supposed to be the policy's main target, which justifies understanding the conceptions of children and childhood that are behind this policy and that gave body to it. What is the idea of a child that guided this programme? What children does it intend to educate? We assume that this view of children affects both the execution and the efficiency of the policies. This should lead us to question if this way of understanding children will prepare them to deal actively and critically with digital technologies and if it will inspire, legitimise and promote 'better childhoods' in the multiple contexts of everyday life. A core question is whether giving children access to technology will per se enable 'better childhoods' or improve their quality of life. Therefore, the question 'more technology, better childhoods?' is the departing point for this article.

\section{The child: human being or human becoming?}

This paper is based on the assumption that the notions of the child and childhood are inherently social and cultural in nature, as several studies on the sociology of childhood substantiate. 
In the late 1980s, early 1990s, children and childhood became objects of great interest to the academy and assumed increased visibility in public policy agendas, with the adoption of the Convention on Child Rights by the United Nations in 1989 playing a significant role. This legal document, mandatory for all countries that have ratified it, also marks a turning point in the way of looking at children in relation to the universe of adults (Renault, 2002 and Taylor, 2002 cit. in Almeida, 2009: 20). Apart from making the child a subject of rights, with rights to protection, provision and participation, the Convention enshrines the "best interest" of the child, recognizing he or she as a 'human being' who has a 'voice' worth listening to.

Indeed, new paradigms for understanding the worlds of childhood and children's lives did not begin to build up until the second half of the twentieth century. The social, historical and cultural contexts that involve the child began to be studied by the humanities and the social sciences, widening perspectives in relation to the classical concepts of socialization and breaking down some of the old dichotomies, namely the dichotomy of nature/culture.

For decades, the biological paradigm, based on Darwin's evolutionary perspective, presupposed the natural, and therefore universal, character of childhood (Almeida, 2009). This perspective did not consider the historical, social or cultural context of children's lives. As Belloni stated,

"The prevailing view about childhood in the humanities especially emphasized the child as a being in formation, incomplete, the future man present in the 'little man' and his ability to become an adult, within an evolutionary perspective heavily inspired in Darwin's theory” (Belloni, 2009: 121).

This evolutionary logic of the development of children has also left its mark on the developmental psychology perspectives of the early twentieth century. Although the principles involved here are based on constructivism, the prevalent idea is still that the child develops into an adult in a continuous and linear way and by predictable and universal stages (Almeida, 2009). The assumptions about the universality and the irrationality of childhood are also present in the theories of socialization produced within the sociology of the 1950s and 1960s (Almeida, 2009), particularly in the functionalist view of Talcott Parsons to whom the 
child is "a passive, incomplete and an individual being who must be appropriated, moulded, prepared to join the social system" (Almeida, 2009: 28).

This vision of the child as an unfinished being, incomplete, incompetent and dependent persisted and still continues to dominate current thinking about children and growing up (Lee, 2001). It was precisely in opposition to the biological and psychological paradigms, which take childhood as a natural category that the sociology of childhood began to make a stand (Prout, 2005). Indeed, during the last decades of the twentieth century, a new sociological paradigm of childhood that perceives childhood as a social construction and not as a natural reality started to materialise (Qvortrup, 1991). Nevertheless, a trend still seems to persist: in the definition of policies, either in the speeches about children or in professional practices that involve them, children continue to be seen as they will be in the future, as the adults they will become, instead of thinking of them and working with them as the beings they are in the present, with their own characteristics, the subjects of different stories and trajectories, living in distinct situations.

Even though today's child is considered in western countries to be a subject of rights and an actor of his or her socialization process, the conceptions and the representations of children present in both political discourses and the reallife situations of children are still paradoxical. The idealized child of political discourses and programmes and the child living a 'real' life with distinct stories, life situations and contexts are already in opposite poles.

Despite the attempts of sociologists of childhood to surpass the common sense division between adult 'human beings' and child 'human becomings' (Qvortrup, 1991), considering that "all humans, regardless of chronological age, are and should be treated as 'beings"' (Lee, 2001: 2), that division continues to be a widespread tendency. Overcoming this dichotomous vision does not mean denying the differences between adults and children. Instead, it means that children should be seen as beings alongside adults, that they should be treated equally and that their views and perspectives should be recognized. Further, it means surpassing the vision of 'beings' (adults) as complete and the vision of 'becomings' (children) as incomplete.

Lee shows how the being/becoming division "is a product of historical development and that, as such, it is open to change" (2001: 6). In continuation, 
Lee also shows the contemporary erosion of this division induced by global economic, political and social changes. Lee argues that in the uncertainty of the age in which we now live "it is hard to believe in the standard image of adulthood" (2001: 6), adding that "our main model of human 'being' is losing its socio-economic supports" (Lee, 2001: 37). This perspective is even more relevant in the current time, which is characterized by the serious economic, political and social crisis that caused huge uncertainty in the lives of all citizens. In fact, today's adulthood can no longer be assumed to be stable and complete (Lee, 2001:103).

To recognize children as beings is not to pretend that they do not change (Lee, 2001: 54) or limit the growing up process to a set of possibilities. To overcome the dichotomy of adult-being/child-becoming means that the child is not seen or deduced from the adult, but he/she is rather "in a dynamic between two conditions that are built on reciprocity" (Almeida, 2009: 24). As observed by Harden et al. (2000, paragraph 1.1), "childhood is primarily a relational term, grounded in its relationship of difference with adulthood".

\section{Conceptions of the child as a media user}

The different ways of approaching the relationship between children and media have certain underlying models of child and childhood. Academic studies and the media themselves often echo different concepts and representations of children, depending on both the theoretical framework they employ and their objectives. The notions of children and childhood shared in current discourses on the relationship between children and media, whether in speech produced by the media or their professionals are often paradoxical (Pereira, 2007). According to their interests at the moment, families, the media, and governmental entities alternate between the defence of the notion of a 'childagent' who is active and critical towards the content broadcasted by the media and the notion of a 'child-subject' who is passive, vulnerable and in need of protection. These notions are closely linked with concerns about the effects of the media on children, which is a recurrent phenomenon.

In its relationship with the media, the child is seen from four coexistent perspectives. One of these perspectives, which can be characterized as protectionist, emphasizes the deficit dimension of children and childhood and the 
vulnerability of the child audience. It implies a vision of a defenceless child, strongly influenced, vulnerable and unprotected. The prevailing idea is that children need to be protected from the possible negative effects that the media can have in their socialization process. This perspective also includes preventive strategies for inoculating children against the effect of media. This protectionist approach falls within the theoretical paradigm based on direct effects of the media that was dominant until the late 1960s.

Another perspective is based on the idea of the child as a consumer and prescriber of consumption. It is almost the opposite of the previous view. Unlike the view of a passive child before the media, it adopts a vision of an active child who knows what he or she wants and is eager to consume, a potential audience and customer. This approach emerges within a global society characterized by consumption and a 'world culture'. It contains roots of a consumerism ideology and is mainly supported by companies and professionals within advertising and marketing. This conception of the child is as homogeneous and undifferentiated as the protectionist perspective. It talks about children as a universal category rather than addressing specific children living in particular and diverse historical, social and cultural contexts.

A third perspective is characterized by a technological and modernizing vision. It is particularly dominant in the discourses of business decision makers and policy makers and in governmental programmes aimed at diffusing and implementing ICT at schools and providing children and young people with access to technologies. This approach emphasizes the wonder of technology, as if it were a magic solution for the process of teaching, learning and educational success. Children are seen as competent subjects in accessing and handling technologies, as if the access were the condition to learn to retrieve, assess, store, produce and exchange information and to communicate and participate in networks.

To these three perspectives, which are clearly focused on the media, content and technologies, we added another view that focuses on the empowerment of children. This approach considers that children can develop active and critical attitudes and practices in relation to media, but they need support, encouragement and guidance, in a word, mediation. Therefore, children are not naturally 
and spontaneously critical subjects; they need support to develop these capabilities.

\section{Methods}

Based on the Portuguese governmental programme 'e.escolinha', this paper intends to analyse how children are envisaged and represented by technological public policies on education. It starts with the premises that children are human beings and not human becomings and that the notions of the 'child' and the 'child media user' are political in nature.

For this study, we selected a set of sources that were submitted to a systematic analysis. The sources are as follows:

- Resolution of the Technological Plan for Education (Resolução do Conselho de Ministros, 2007);

- The videos used to launch and publicize the 'e.escolinha' programme': (1) "Launch of the 'e.escolinha' initiative and the 'Magalhães' Computer", 2008; (2) "Intel Learning Series - The Intel powered Classmate PC in Portugal', n/d; (3) “"Magalhães' - My first laptop” by Microsoft, 2009.

- Documents of the twenty-six minutes, and the final report, of the Commission of Parliamentary Inquiry to the Foundation for Mobile Communications ${ }^{4}$;

- Semi structured interviews (11) of policy-makers and deputies of the parliamentary opposition parties (Table 1$)^{5}$.

\footnotetext{
3 These are the most representative official videos specifically produced by the government or related companies (such as Microsoft) to launch and present the initiative.

${ }^{4}$ This Provisional Parliamentary Committee Inquiry was constituted as a result of an official request by three members of the Social Democratic Party (then the main opposition party to the Socialist government) to assess the performance of the government in relation to the Foundation for Mobile Communications (FMC) under the Articles of the Constitution of the Portuguese Republic. The FMC is a Portuguese foundation of private law that is responsible for managing the 'e.escola' and 'e.escolinha' programmes.

5 For this paper, we selected eleven of the twenty-two interviews conducted within the research project. The criterion for this selection was the political position of the interviewees since this paper aims to examine the ways in which the child and the child media user are presented in the discourses of political agents (the policy makers involved in the creation and implementation of the 'e.escolinha' initiative and the deputies of the opposition parties).
} 
Table 1: List of the interviewees

\begin{tabular}{|c|c|}
\hline & Interviewees professional position \\
\hline \multirow{7}{*}{ 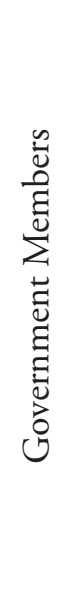 } & $\begin{array}{l}\text { Minister of Education of the XVII Constitutional Government (March } \\
2005 \text { - October 2009) }\end{array}$ \\
\hline & $\begin{array}{l}\text { Minister of Education of the XVIII Constitutional Government (October } \\
2009 \text { - June 2011) }\end{array}$ \\
\hline & $\begin{array}{l}\text { Minister of Education of the XIX Constitutional Government (2011 - } \\
\text { present) }\end{array}$ \\
\hline & Secretary of State of Public Works and Communications \\
\hline & Assistant Coordinator of the Technological Plan \\
\hline & National Coordinator of the Lisbon Strategy and the Technological Plan \\
\hline & Coordinator of the Educational and Technological Resources Team \\
\hline \multirow{4}{*}{ 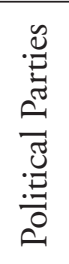 } & Deputy of the Popular Party (PP) \\
\hline & Deputy of the Social Democratic Party (PSD) \\
\hline & Deputy of the Portuguese Communist Party (PCP) \\
\hline & Deputy of the Left Block Party (BE) \\
\hline
\end{tabular}

These sources were inserted into the qualitative analysis software 'NVivo' and analysed through a grid that includes different categories. For this paper, two categories were identified and analysed: (1) conceptions of the child; (2) conceptions of the child media user.

In order to understand how children experienced this specific policy in their everyday lives, the paper gathered children's opinions about this governmental programme. These opinions were collected by a questionnaire applied to children in the $3^{\text {rd }}$ and $4^{\text {th }}$ grades of the 1 st cycle of Basic Education. From a total of seventy-two public primary schools of the municipality of Braga (a city in the North of Portugal) thirty-two schools were inquired. The final sample is constituted by 1,517 children $^{6}, 51 \%(\mathrm{~N}=759)$ boys and $49 \%(\mathrm{~N}=742)$ girls (16 didn't mention their genre). $48 \%(\mathrm{~N}=729)$ pupils are from the $3^{\text {rd }}$ grade and

\footnotetext{
6 The total amount of questionnaires collected is 1,527 but ten were excluded due to incorrect completion.
} 
$52 \%(\mathrm{~N}=788)$ from the $4^{\text {th }}$ grade $^{7}$. From the 1501 children who expressed their age, $20 \%(\mathrm{~N}=298)$ are 8 years old, $50 \%(\mathrm{~N}=753)$ are 9 years old, $27 \%(\mathrm{~N}=410)$ are 10 years old, and 3\% $(\mathrm{N}=40)$ are of other ages.

The present analysis of the questionnaires is centred only on children's perspectives on the impact of the 'One Computer per Child' programme on their lives, particularly at home and at school. From these specific data, we aim to discuss the importance of this kind of governmental policy for young people, listening to their opinions, beliefs, concerns and expectations.

The quantitative data provided by the questionnaire was analysed using the software SPSS (Statistical Package for the Social Sciences). The open questions were categorized and analysed using the qualitative data analysis software NVivo.

\section{Results and discussion}

The rhetoric used in the technology policies for education programmes, as well as in the speeches by the policy makers in charge of these programmes, could reveal the place children have in these kinds of policies and the concerns beyond them. The following paragraphs set out the main evidence of the political discourse on children and children technology users. We will look at both sides of this policy: how is it aimed at children and how children experience it.

\section{Children as adults in the making}

An analysis of the information sources shows that children today are a prime target of the power mechanisms. Viewed as an investment in and for the future and as an agent of progress, children are presented based on ideas and goals to achieve and on problems to surpass.

Within the documental sources analysed, there are no explicit references to the concept of the child underlying the programme; instead, there are only references to children as students and to their ages and school levels, reflecting the developmental model of childhood. Because the child is the main intended beneficiary of the initiative, it might be presumed that the policy documents would consider issues related to the social, educational and cultural worlds of

\footnotetext{
7 The research team decided to interview only students of these two levels because they would have an experience of two or three years in using the computer.
} 
children. However, it is only in the minutes and the interviews that it is possible to find explicit and direct references to the way children are positioned. In any case, implicit references in the documents also indicate how children are understood.

In general, children are presented as in the process of becoming something else, as adults in the making or not-yet-adults. There is a huge concern with the future, the competences children should have when adults and, consequently, a preoccupation with offering good conditions in the present to ensure future success. Nevertheless, we observed a silence with regard to what children know in the present, what they are already able to do and what they should learn as children. The child is mainly seen as a student/pupil who should have access to ICT and learn how to use it so as to respond to the demands of the digital era and the requirements of a new working environment. The quotations below illustrate these ideas.

The fact that we have today a generation of young people that had access to a computer can change the skills that this population will have as adults as regards to the conditions of participation, individual development, and access to knowledge and information (Former Minister of Education).

By facilitating and encouraging the access of young people to new technologies and the best educational opportunities, we have created a future generation which is better prepared and equipped with the necessary information to develop the skills and the innovations of tomorrow ('Magalhães - My first laptop' by Microsoft, 2009).

Because we want Portugal in the Information Society where there are genuine equal opportunities also in the access to equipment. Portugal, where the education of new generations accompanies the technological change, where the Information and Knowledge Society reaches every home. We are building a vital change for our future, a future where students, parents and teachers work together in a network, with all the right tools to develop their skills ('Launch of the e.escolinha initiative and the Magalhães Computer', 2008).

In general, children are seen as a homogeneous group with the same interests, the same needs and living in equal social, economic and cultural condi- 
tions. However, one distinction is made: the access 'haves' and 'have-nots'. This aspect is highly emphasized by all of the interviewees and in the minutes as well, as the quotations below illustrate.

Some students with excellent computing environments at home will find an environment at school that will discourage them; some students who had no access to broadband, computers, computing at home will find something in school that they were not prepared for and they will have a direct competitive disadvantage in relation to their colleagues who master technology at home and also at school (National Coordinator of the Lisbon Strategy and the Technological Plan, Minute number 7).

All children should be on equal ground regarding the possible use of these new resources, i.e., the fact they have computers at school and the fact they could work with computers in the classroom is very important for everyone to have the opportunity to really experience and develop this language (interview with the Minister of Education of the XVIII Constitutional Government).

This quotation from the Minister of Education of the XVIII Constitutional Government highlights her perspective on the child, which is very different from all of the other points of view. Perhaps her closer relationship with children's cultural world $s^{8}$ could explain this different vision in relation to the views of the other politicians. The Minister emphasised the uniqueness of each child and the diversity of being a child.

I think all children really have a lot of potential. All are different. The school must provide a match of skills and information, but considering that children are actually all different. Therefore, it is necessary that at the level of the class there is also an individualized monitoring and an individualized interaction between adult and the child (Minister of Education of the XVIII Constitutional Government).

Furthermore, in the interview with this Minister, we found a different form of positioning the child in relation to the adult. They are equal in their difference. The child needs a family, needs an adult, but he/she is not placed in a status of inferiority in relation to the adult.

\footnotetext{
8 Prior to her work as a minister, she had written several books for children.
} 
Firstly, the child is a person with the dimensions that people have. Therefore, hel she is equal to any other of all ages. I think there is also equality in terms of human dignity among all ages, so the first thing is that the child must be a respected person in his/her potential, in his/her characteristics, in his/her way of being. (...) Moreover, precisely because they are human beings that are still dependent, children need that at least one adult to put him/her in first place. This is very important because many children do not have an adult. It is clear that it is better to have two adults, the father and mother, so they need a family (Minister of Education of the XVIII Constitutional Government).

As previously mentioned, the other views are very different. In these views, the core element is the future and preparing to live in the future. The figure below summarizes the dominant view of the child and the main concerns of that policy.

Figure 1: The dominant view of the child

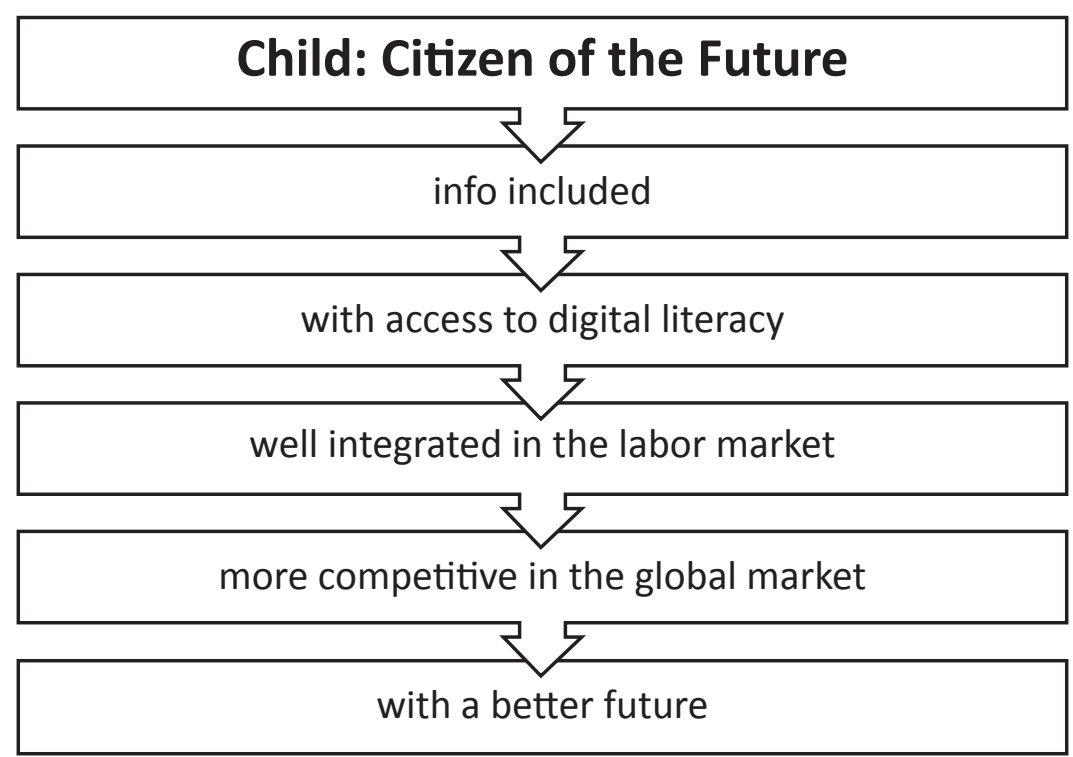


In many aspects, these findings are in line with the conclusions coming from an analysis prepared by Moran-Ellis and Cooper (2000) for the 'Connecting the Learning Society' launched by the UK government in 1997 to institute a 'National Grid for Learning'. As the authors observed, "The child serves here as an abstract cipher which is articulated with the future in an apparently natural and mutually reinforcing relation" (paragraph 1.7). As in our study, the authors have also concluded that the child is positioned as a 'becoming' rather than a 'being', which was not exactly a surprise said the authors, "since these are the defining constructions of children in Western Europe" (Moran-Ellis and Cooper, 2000, paragraph 2.2).

As noted above, this vision of children as 'humans becoming', that is, as future adults, continues to dominate the representation of and the thinking about children. In this kind of policy, a tendency persists to consider children as they should be, instead of understanding how children are in the present, the subjects of their own stories, cultures and contexts, living different situations.

\section{Each child, an explorer: from the passive to the active user}

This section will consider the ways children are understood as media or technology users. Unlike the previous topic, which revealed an almost homogeneous way of perceiving a child, a duality of opinion arises from the concept of 'media user'. However, this duality is not neutral: it is derived mainly from the two groups of interviewees. While the opinions of the governmental members coincide with what is expressed in the documents, different views emerge from members of parliamentary opposition parties.

If for decades the notion of the innocent child as helpless, vulnerable, and in need of protection was evoked by politicians, since the 1990s this discourse has been replaced by a notion of an active child as media user, "an explorer in the ocean of a knowledge society" (Intel Learning Series - The Intel powered Classmate PC in Portugal, $\mathrm{n} / \mathrm{d}$ ).

Of the notions discussed above, the most prominent is the technological and modernizing perspective. This also explains the concentration of the programme on technology and access more than on children. We can even ask the following question: Is this an education programme or a laptop programme? 
The child is seen as a cyber-kid, thirsty for technology and craving access to a computer and Internet.

When the Internet began to be used by people for whom that tool was as natural as the air they breathe, and who were not limited by previous models, the result was Facebook, Twitter, Wikipedia. Everything which is now taken for granted emerged, but that was unthinkable 10 years ago. And this has to do with the ease with which people use media that are at their disposal. Nobody uses technological means more naturally than a generation who has had them as part of their experience from the beginning (Interview with the Assistant Coordinator of the Technological Plan).

The joy of children being able to be connected, to be able to do homework, even if it is to consult the Internet, for them this is learning to do research. And this is reflected in their faces. They are there and do not care about anyone else. It is absolutely fantastic to see this happening ('Intel Learning Series - The Intel powered Classmate PC in Portugal').

Therefore, the child is a technology enthusiast and a natural adept user, which justifies this kind of programmes developed for a young generation interested in technology. Alongside this image, there is a strong belief in the transformative power of ICT and an exaltation of the role of the computer, as can be seen from the statements by the former Prime Minister and the former Ministry of Education (XVIII Constitutional Government):

When a 'Magalhäes' computer enters a house, this house will never be the same. 'Magalhães' is a computer to be used from ages 7 to 77 . It is a computer that does everything we need (Former Prime Minister of Portugal in a statement to the RTP afternoon news bulletin, 23rd September 2008).

'Magalhães' is a powerful means that can make everything change: it can make a child who has difficulty in learning to read learn faster and better (Former Minister of Education in newspaper 'Diário de Notícias', 22nd May 09).

For the politicians in charge of the programme, the computer could transform and improve children's skills to learn. The majority of the discourses present a kind of marketing pitch on the potential of ICT to transform the child 
into a successful adult and into a competent professional in an increasingly competitive labour market.

Education is assigned the role of preparing new generations for the knowledge society and school is seen as a prime site for this. ICT is regarded as a key tool for learning in the new era and preparing for the future. The key concerns are educational, integrating ICT into the classroom and making the process of teaching and learning more interesting and interactive.

We find here, however, some inconsistency. On the one hand, the natural appetite of the child for technology is exalted; on the other, the child is presented "as 'needy' in terms of gaining the skills needed to use ICT successfully" (Selwyn, 2003: 364). Schools and teachers should train children in the use of ICT, preparing them for a digital future?

From the analysis of the sources emerges, however, a portrayal of the child media user somehow different from the 'modernizing' perspective. Some of the interviewees, especially members of the opposition parties, are a bit sceptical about the natural digital competence of children and the ICT power to transform school and education. They praise the programme in some of its aspects, for example, universal access, but they are also critical of the way the programme was designed and implemented. They emphasise the need to help children to develop ICT skills in a powerful technological world.

It is not enough to put a computer in front of a child and let him/her take it home, have it at home, and play in the late afternoon and evening and go to the Internet when they want, watch what they want. There should be concerns related to the adequacy of strategies and programmes in terms of curriculum and pedagogical and educational aims; there should be concerns related to the kind of encouragement and the kind of "proposal" that we have to present to children about what to do with technology. And this was not something conceived from

\footnotetext{
9 Once again, we highlight the perspective of the minister who presided over the Minister of Education of the second Socialist government responsible for continuing this programme. Although she considers that children have a natural appetite for technology, she also considers that this appetite, by itself, is not enough to learn to use the computer and its languages. In her opinion, the universal access to ICT must be guaranteed but this has to be accompanied by digital literacy goals. It is important to note that this minister was not responsible for creating and implementing the programme 'e.escolinha' involving the distribution of the 'Magalhães' computer. When she took office in the XVIII government, the programme was already running. This does not mean that she, as Minister of Education, could not have had an important role in changing the policy of a programme too focused on technology and access.
} 
the beginning (Interview to the Deputy of the Portuguese Communist Party - PCP).

The idea of discovering, experiencing and playing on... the 'Magalhäes' computer works somewhat well, such as the discovery of a new world. It should be used in a properly structured academic path so that the relationship between children and the 'Magalhäes' computer could be more fruitful. It did not happen (Interview to the Deputy of the Left Block Party - BE).

The vision of the child as a 'becoming' rather than a 'being' is transversal to all the discourses. But the perspective of empowering children to use digital media through media literacy is quite absent both in political discourses and in the programme objectives.

\section{From the interests of the state to the interests of the child: How do children experience this policy?}

This governmental programme is a good example of a public policy much more centred on technology and on the context (school) than on its subjects.

The child oscillates between two poles: the child idealized from the norms and representations and the child living the situation of life as it is. A heavily underlined aspect of this policy concerns the families of children. This emphasis causes some confusion in relation to its main recipients: is it a policy for schools, for children or for families? The answer to this question is not consensual. In fact, this was an issue discussed at the parliamentary inquiry and reported in the minutes. In this debate, the Minister of Education of the XVII Constitutional Government defended the view she stated in the interview: the programme is mainly for families.

As you know, Portugal is a country with strong geographical, social and economic asymmetries and there are strong constraints in the access to these resources. As a result, in 1999-2000 and again in 2005 the government set out as a major area for assistance the provision of support to families in accessing resources that allow access to information and knowledge. Which families? When discussing 'which families' the priority is families who have children, who have teenagers in school, because they have a greater potential considering what the objectives 
of the development of the information society are. (...) A 15-year-old student of secondary education more easily convinces the family of the importance of access to a computer than an 11 or 12-year-old, because it is about families that we are dealing with and not schools (Minister of Education of the XVII Constitutional Government, Minute number 14, 2010).

The Coordinator of the Educational and Technological Resources Team shares the same opinion:

The computer Magalhães had a great particularity. It was not an initiativeunlike all other previous and later ones - for providing equipment to schools. All other previous initiatives were to equip schools. In this case, it was the student and family. Therefore, the importance of Magalhäes was to make it possible for a device that in many Portuguese families did not exist, either for parents or for children, to first make its way into these families, these homes. This is the value I see in it, a social value, one of equal opportunities (Interview with the Coordinator of the Educational and Technological Resources Team).

The opinion of the Minister who succeeded the XVII Minister differed. For the Minister of Education of the XVIII Constitutional Government the focus of this policy is on education and school:

It seemed crucial for the development of education and for encouraging the skills of children, especially in this area, which is an essential area that schools take as an educational area. In other words: the competences in the area of new technologies, the acquiring of instruments of thought and the mastering of these languages are crucial in the contemporary era (Minister of Education of the XVIII Constitutional Government).

Without denying these tremendous adult efforts to prepare children for the future, providing them access to a computer and the Internet on a basis of equality of opportunities, in-school teaching/learning on children's technology use also acknowledges the ways children make their own uses: transforming, redefining and recreating the prerogatives established by adults. This policy 
reflects what is suggested by Jenkins (1998): “Children's culture is shaped at the global level through powerful institutions and at the local level through individual families. Through these everyday practices, the myth of the innocent child gives way to the reality of children's experience" (Jenkins, 1998: n/p). Jenkins argues,

Recent studies of childhood have generated a more complex picture of the power relations between children and adults. Parents, schoolteachers, church leaders, social reformers, the adult world in general, are powerfully invested in 'fixing' children's identities. (...) Children's culture is shaped by adult agendas and expectations, at least on the site of production and often at the moment of reception, and these materials leave lasting imprints on children's social and cultural development (Jenkins, 1998: n/p).

Within this formulation, children's culture is not something that happens to children or something that is provided to them. Children are participants and contributors to that culture, at least at the moment of reception. This is what 1,517 children expressed through the questionnaire applied within the research project.

\section{What children have to say?}

A main objective of the questionnaire was to understand children's opinions on the programme 'e.escolinha' and on the 'Magalhães' computer. The public discussion about this issue, and mainly what was conveyed by the media, rarely listened to the children. Actually, their voices were often neglected. As researchers on this topic, it was certain for us that children had a say on the subject and should be listened to. Therefore, when we invited them to express their opinions on the programme 'e.escolinha', the overwhelming majority of children (approximately 90\%) approved of the initiative, highlighting the fact that it allowed students to have a personal computer (Figure 1). Justifying their answers, a 10-year-old girl stated, "It was a good experience. I never had a computer just for me" and an 8-year-old boy said that "The good thing that Magellan brought to my life was to learn to work with a computer".

The Figure below presents other opinions about this governmental initiative. An aspect that should be highlighted is that more than half considered that 
the government should have asked for children's opinions on this measure. But the percentage that has a contrary opinion $(30,5 \%)$ should not be disregarded. This also tells us about the consciousness that children have of their place in society and their notion of the value of their opinions in this kind of policies, that is, in 'adult issues'. Somehow, the perceptions of children reflect a broader perception of society about the importance of children's participation in such matters.

Figure 1: Children's opinions on the distribution of the 'Magalhães' computer by the Portuguese government

\section{What do you think of the government's idea of distributing the 'Magalhães' computer to all children in the $1^{\text {st }}$ cycle?}

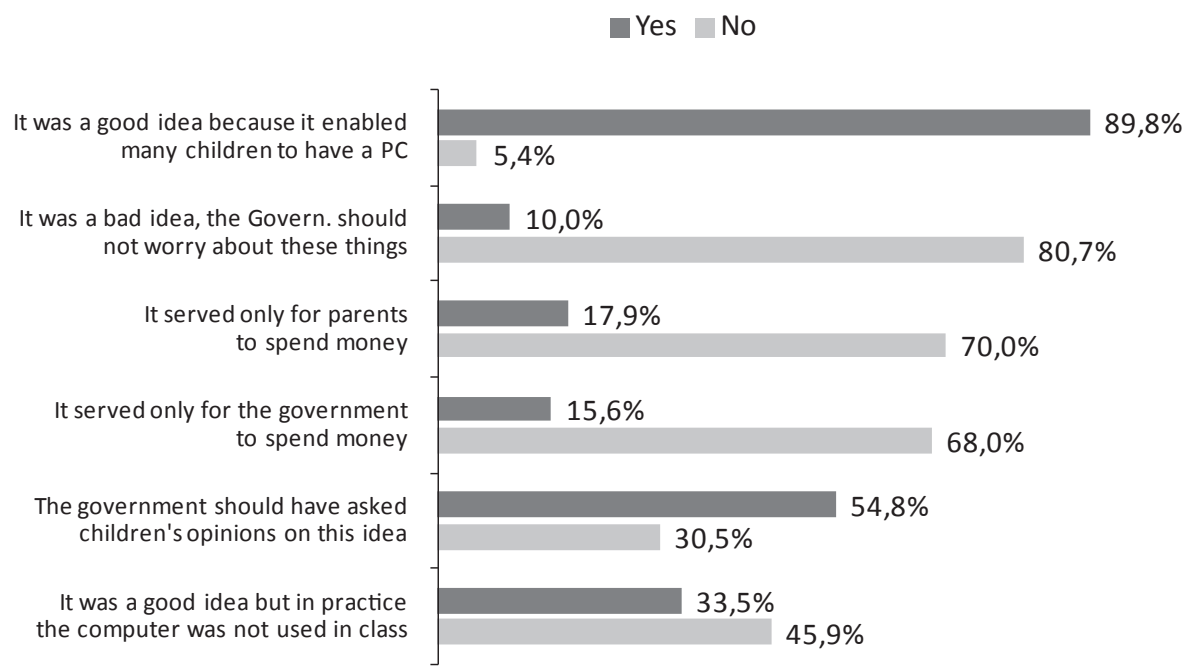

This feeling of the importance of ownership of a technological device - a personal computer - is also evident in the percentage of children who acquired the computer: $98.2 \%$ (1490), thus showing how children welcomed the initiative. That feeling is also highlighted in the way children negatively reacted to the suspension of the measure (Figure 2). 
Figure 2: Students' opinion on the decision of the Ministry of Education to suspend the delivery of 'Magalhäes' computers $(N=1439)$

\section{What do you think of the decision of not delivering more computers to students?}

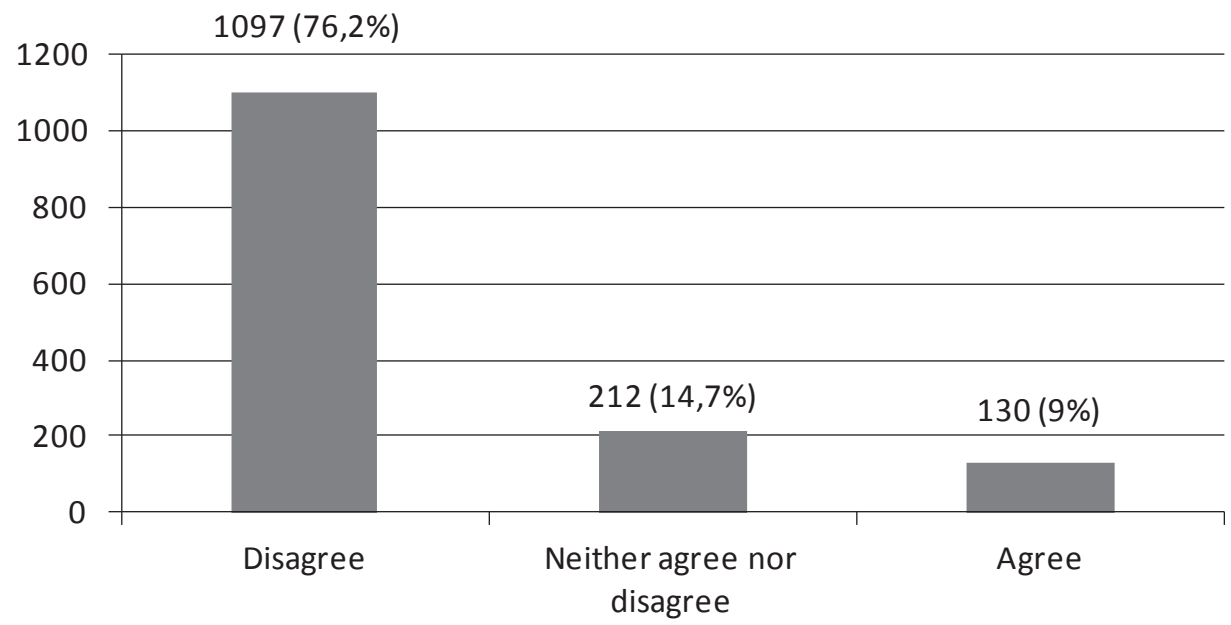

A large percentage of children (76.2\%) disagree with the decision of the new Ministry of Education ${ }^{10}$ of cancelling the distribution of computers, in 2011. Many children invoked the "need to access a personal computer" as the main factor for their disapproval while others referred to the situation of injustice for other children who would not have the same opportunity to access the equipment. Those who agree with the decision (9\%) cited as main reasons the poor financial situation of the country, considering that it is a waste of money, and the bad quality of the computer. The quotations below, from the open questions, illustrate the opinions of children in this matter:

I don't agree because if the Ministry of Education does not deliver the computers it would be unfair to students, because the older students have a 'Magalhäes' and the new students do not (Girl, 8 years old, $3^{\text {rd }}$ grade).

\footnotetext{
${ }^{10}$ The Ministry of Education of the XIX Portuguese Constitutional Government.
} 
I would not agree because 'Magalhães' served for many things, among them, to learn, and if we had it, others also have the right to have it (Girl, 9 years old, $4^{\text {th }}$ grade).

On the one hand it is good because several children are playing games and going on the internet and are not using the computer for learning; on the other hand it is bad because children can learn through it (Girl, 10 years old, $4^{\text {th }}$ grade).

The government is in a political position and owes many millions of euros and it would only worsen the situation if it distributed more 'Magalhães' (Boy, 10 years old, $4^{\text {th }}$ grade).

The positive opinion regarding the opportunity to access the computer 'Magalhães' is not so enthusiastic when children were asked about the contribution of this computer to the learning process in which they were involved. In fact, children stand out as major contributors to its activity aspects: spending their free time better (83\%), learning how to research (78\%), having access to a computer $(68 \%)$, having an easier access to information $(63 \%)$ and having access to the Internet (62\%); thus, enhancing skills clearly related to research. However, the contribution of 'Magalhães' to activities oriented to "educationallearning", which implies a more reflexive approach in the sense that it is nearest the dynamics of a "learning curriculum", were mentioned by only about half of the students: learning to read better (53\%), better resolving exercises $(52 \%)$, doing homework better (46\%), having better school outcomes (40\%).

This scenario shows that children value the government programme more for providing an opportunity for universal access to a technological means, which they recognize provides both a chance to develop their technical skills and individual enjoyment, rather than regarding it as a tool to enhance educational gains in the context of school. The extent to which this resource is used in school is dependent on the specificity of the school and/or the methodology adopted by each teacher leading to a division of opinions on the use of computers in the classroom.

The non-use of the 'Magalhães', or its underuse compared to expectations, is a feature that could explain the difference of perspectives that students show in relation to the effective contribution of the government measure to their activities. Indeed, this can be explained, in our view, by the frustration of some 
children with the use of the computer at school associated with the fact that, in certain cases, the supply of technology available in the household was higher (as indicated by $51 \%$ who had other computers at home they preferred over the 'Magalhães' computer).

Nevertheless, most children positively evaluated the contribution of 'Magalháes' to their lives, as the following quotations illustrate:

It was a good experience, I never had a computer just for me (Girl, 10 years old, $4^{\text {th }}$ grade).

The good thing about this computer: it was a computer that only I had control over (Girl, 10 years old, $4^{\text {th }}$ grade).

The good thing that 'Magalhäes' brought into my life was that I was able to work with a computer (Boy, 8 years old, $3^{\text {rd }}$ grade).

It didn't bring almost anything but brought me a little responsibility because having a computer just for us is a responsibility (Girl, 8 years old, $3^{\text {rd }}$ grade).

The good thing 'Magalhäes' brought into my life was more learning for the future (Girl, 9 years old, $4^{\text {th }}$ grade).

Again, children emphasize the possibility of having access to a personal computer, the aspect they evaluate as more positive. In this respect, one can say that the goal of the programme 'e.escolinha' was reached. The largest gap is in the computer uses, especially in the context of school. The promoters of the programme - mainly the government and industry - and the official documents had (and created) the expectation that the computer would revolutionize the process of teaching and learning. Somehow, children also created these expectations. In fact, in general they positively evaluated the programme, but they expected more, especially regarding its impact on school learning.

\section{Final remarks}

Universal access to the new tools of the information and knowledge society became a central goal of the technological policy for education of the XVII and the XVIII Portuguese socialist governments from 2005 to 2011 . However, this policy has a paradoxical vision of the child as a media consumer and computer 
user. On the one hand, it presents children as media/computer competent, as if they had been born with a natural competence to use technology. On the other hand, it requires educational policy programmes, such as 'e.escolinha', to ensure the acquisition of digital skills. Nevertheless, children are defined mainly as pupils who need to have access to technology to face increasingly complex societal changes.

The documents and policy statements reveal a huge concern with the future and the competences children should have as adults. It ascribes to digital technologies the role of an important tool to help children manage a distant future. Consequently, little attention is paid to the present child who is living his or her childhood today under certain circumstances. In fact, the child is seen as a future adult and a citizen of the future, that is, an adult in the making.

Technology is presented in a scenario of fascination and wonder with the intrinsic power of innovation. These discourses are not neutral, as technology is neither neutral nor asocial. Technology is part of culture and it opens new ways of communicating and creating relationships. Therefore, as Selwyn observes, "We must also be aware of the socially constructed nature of 'technology' as a discursive devise" (Selwyn, 2003: 353).

When examining these kinds of policies it is therefore important to consider the representations of technology and its uses in situ. The rhetoric of the discourses sometimes hides or overlooks both the agency of children and the multi dimensions of technology uses. The analysis has provided a point of contrast between an idealised policy, the mundane realities of children and the complexity of using the 'Magalhães' computer.

In some ways, these findings were not a total surprise. Such conclusions have also emerged from other studies (Selwyn, 2033; Facer et al., 2001; MoranEllis and Cooper, 2000) that reveal "a stark contrast between the realities of children's ICT use with contemporary media and political portrayals of children and technology" (Selwyn, 2003: 352). Thus, there are characteristics and trends that are common to these kinds of political programmes, regardless of the country and its culture. Selwyn summarizes these common characteristics:

The notion of the child computer user has been used by state and commercial interests to rehearse, clarify and promote a range of societal, economic and political concerns over the role of new technologies in society. (...) The notion of the child computer user is, to a large degree, merely a means of 
persuasion and promotion on the part of the key commercial and political guiding interests of the information age (Selwyn, 2003: 374).

This analysis finds its importance in the central place that media and digital technologies have in children's cultures and the crucial role these media play in the construction of contemporary childhood. It can also help to reveal the political interests and economic concerns that shape educational programmes in the information and communication age. 


\section{Acknowledgements}

This paper draws on a research project, Navigating with 'Magalhäes': Study on the Impact of Digital Media on Schoolchildren, directed by the author. The project, conducted at the Communication and Society Research Centre at the University of Minho, Portugal, is financially supported by the Portuguese Foundation for Science and Technology [PTDC/CCI-COM/101381/2008] and co-funded by the European Regional Development Fund [COMPETE: FCOMP-01-0124-FEDER-009056].

\section{References}

Almeida, A. (2009). Para uma sociologia da infância. Jogos de olhares, pistas para a investigação. Lisboa: Imprensa de Ciências Sociais.

Belloni, M. (2009). O que é a sociologia da infância. Campinas: Editora Autores Associados Ltda.

Facer, K., Furlong, R., Furlong, J. \& Sutherland, R. (2001). Constructing the Child Computer User: From Public Policy to Private Practices. British Journal of Sociology of Education, 22(1), 91-108.

Harden, J., Scott, S., Backett-Milburn, K. \& Jackson, S. (2000). Can't Talk, Won't Talk?: Methodological Issues in Researching Children. Sociological Research Online, 2(5). Accessed 05.05.2013. URL: http://www.socresonline. org.uk/5/2/harden.html.

Jenkins, H. (1998). Introduction: Childhood Innocence and Other Modern Myths. In H. Jenkins (ed.), The Children's Culture Reader. New York: New York University Press. Accessed 02.05.2013. URL: http://www.worldcat. org/title/childrens-culture-reader/oclc/183926687/viewport.

Lee, N. (2001). Childhood and Society. Growing up in an Age of Uncertainty. Maidenhead: Open University Press.

Moran-Ellis, J. \& Cooper, G. (2000). Making Connections: Children, Technology, and the National Grid for Learning. Sociological Research Online, 3(5). Accessed 01.04.2013. URL: http://www.socresonline.org.uk/5/3/ moran- ellis.html. 
Pereira, S. (2007). Por Detrás do Ecrä: Televisão para Crianças em Portugal. Porto: Porto Editora.

Pereira, S., Pereira, L. (2013). Digital Media in Primary Schools: Literacy or Technology? Analysing Government and Media Discourses. Educational Policy, Sage Publications (Published online before print June 20, 2013, Doi: 10.1177/0895904813492378).

Ponte, C. (2012). Digitally Empowered? Portuguese Children and the National Policies for Internet Inclusion. Estudos em Comunicação, 11, 49-66.

Prout, A. (2005). The Future of Childhood: Towards the Interdisciplinary Study of Children. London: Routledge/Falmer.

Qvortrup, J. (1991). Childhood as a Social Phenomenon - An Introduction to a Series of National Reports. EUROSOCIAL Reports Volume 36. Vienna: Centre for Social Welfare Policy and Research.

Resolução do Conselho de Ministros [Resolution of the Council of Ministers] n. ${ }^{\circ}$ 137/2007, Plano Tecnológico da Educação [Technological Plan for Education]. Diário da República, $1^{\text {a }}$ série - N.o 180, de 18 de setembro de 2007. Accessed: 10.11.2010. URL: http://www.umic.pt/images/stories/ publicacoes200801/RCM_137_2007.pdf.

Selwyn. N. (2003). Doing IT for the Kids: Re-examining Children, Computers and the Information Society. Media Culture Society, 25(3), 351-378. 